Check for updates

Cite this: RSC Adv., 2017, 7, 31663

\title{
Ir/C and Brpnsted acid functionalized ionic liquids: an efficient catalytic system for hydrogenation of nitrobenzene to $p$-aminophenol
}

\author{
Hong Wang, Taotao Jiang, Lei Ma, (iD * Hanbing Wang, Xiaoliang Xu, Chunshan Lu \\ and Xiaonian $\mathrm{Li}^{*}$
}

In this study, we found that the phenylhydroxylamine intermediate could desorb more easily from an Ir surface than from a Pt surface, which is beneficial for inhibiting the over-hydrogenation of phenylhydroxylamine to aniline. On the other hand, the Brpnsted acid functionalized ionic liquids with sulfonic acid and bisulfate anions were acidic enough to catalyze the Bamberger rearrangement to form $p$-aminophenol from phenylhydroxylamine. On this basis, a new catalytic system constructed by $\mathrm{Ir} / \mathrm{C}$ and Brpnsted acid functionalized ionic liquid was applied, for the first time, to the one-pot hydrogenation of nitrobenzene to $p$-aminophenol. Our results indicate that the PAP selectivity of $\mathrm{Ir} / \mathrm{C}$ and $\left[\mathrm{SO}_{3} \mathrm{H}\right.$-bmim] $\left[\mathrm{HSO}_{4}\right] \mathrm{Br} \varphi n$ sted functionalized ionic liquid was far more than that of the traditional $\mathrm{Pt} / \mathrm{C}$ and sulfuric acid catalyst system. Furthermore, the dually functionalized ionic liquid $\left(\left[\mathrm{HSO}_{3}-b-\mathrm{N}-\mathrm{Bu}_{3}\right]\left[\mathrm{HSO}_{4}\right]\right)$ can be used simultaneously as an acid catalyst and also as a surfactant, due to its higher lipophilicity. Therefore, our new catalytic system has unique advantages in the hydrogenation of nitrobenzene to $p$-aminophenol.

Received 27th April 2017

Accepted 7th June 2017

DOI: $10.1039 / c 7 r a 04722 c$

rsc.li/rsc-advances different from those on Pd; Ir was more beneficial to the formation of PHA intermediates than Pd. ${ }^{13}$ Since PHA is the most important intermediate for the hydrogenation of NB to PAP, we supposed that the special adsorption properties of Ir might be favourable for the formation of PAP.

Sulfuric acid is usually used as the acid catalyst for the conversion of PHA to PAP through the Bamberger rearrangement, which causes some serious problems like considerable amounts of effluents and equipment corrosion..$^{14,15}$ In the past few years, chemists have investigated some new acidic catalysts, including solid acid ${ }^{16-21}$ and the $\mathrm{CO}_{2} / \mathrm{H}_{2} \mathrm{O}$ system, ${ }^{22}$ to replace sulfuric acid for this transformation, but the results have not been ideal, due to the rapid deactivation or insufficient acidity of these acid catalysts. ${ }^{23-25}$

As a kind of environmentally friendly acid catalyst, $\operatorname{Br} \varphi n s t e d$ acid functionalized ionic liquids (BFILs) have the advantages of solid acids in addition to the characteristics of liquid acids. also be generated for the over hydrogenation of PHA in this transformation (Scheme 1).

The one-pot hydrogenation of NB to PAP involves two kinds of catalysts: the hydrogenation catalyst and acid catalyst. The supported noble metal (e.g. Pt, Pd or Au) catalysts are usually used as hydrogenation catalysts for the reduction of the nitro group. ${ }^{8-12}$ In our previous study of the selective hydrogenation of halogenated nitrobenzene, we found that the adsorption properties of halogenated nitrobenzene on Ir were significantly

Institute of Industrial Catalysis, Zhejiang University of Technology, State Key Laboratory Breeding Base of Green Chemistry Synthesis Technology, Hangzhou, 310014, P. R. China.E-mail: malei@zjut.edu.cn; xnli@zjut.edu.cn

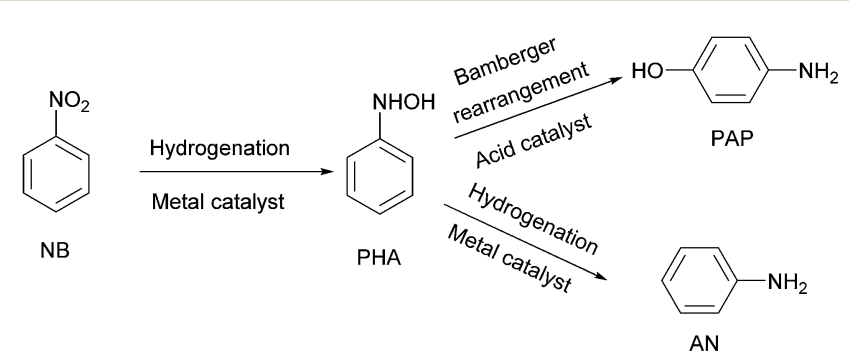

Scheme 1 Hydrogenation of nitrobenzene to $p$-aminophenol. 
BFILs also have unique properties like water-stability and structure-adjustability, which make them widely used in the field of esterification, ${ }^{26,27}$ hydrolysis, ${ }^{28,29}$ alkylation, ${ }^{30,31}$ the Biginelli reaction, ${ }^{32}$ hydrodeoxygenation, ${ }^{33}$ and Beckmann rearrangement, ${ }^{34}$ instead of traditional mineral acids. Recently, Cui et al. reported their work on the one-pot hydrogenation of $\mathrm{NB}$ to PAP using BFIL $\left[\mathrm{HSO}_{3}-b-N-\mathrm{Me}_{3}\right]\left[\mathrm{HSO}_{4}\right]$ as the acid catalyst and $\mathrm{Pt} / \mathrm{SiO}_{2}$ as the hydrogenation catalyst. ${ }^{35}$

Based on our previous research results and the performance of BFILs in the hydrogenation of NB to PAP, we constructed a new catalytic system by the combination of Ir/C and BFILs to catalyze the one-pot hydrogenation of NB to PAP. The catalytic performance of this system was then studied and compared with that of the traditional $\mathrm{Pt} / \mathrm{C}$ and sulfuric acid system. In addition, considering the structure-adjustability of BFILs, we also wanted to modify the structure of the BFILs to improve the lipophilicity, and found real dual functionalized ionic liquids with the functions of acid catalyst and surfactant. The dual functionalization of acidic ionic liquids might afford an opportunity for us to carry out the hydrogenation of NB to PAP without adding surfactant.

\section{Experimental}

\section{Materials}

$N$-Methylimidazole, triethylamine, tripropylamine, tributylamine, pyridine, 1,4-butanesultone and hexadecyl trimethyl ammonium bromide (CTAB) were purchased from Aladdin Reagent Co. Ltd. Sulfuric acid, nitrobenzene, aniline ethyl acetate, diethyl ether, acetonitrile, ethanol and isopropanol were purchased from Shanghai Lingfeng Chemical Reagent Co. Ltd. All reagents and raw materials were commercially available and used without any further purification.

\section{Preparation of catalysts}

Hydrogenation catalysts. The commercial coconut shell activated carbon with Brunauer-Emmett-Teller (BET) surface area of $1662 \mathrm{~m}^{2} \mathrm{~g}^{-1}$ was provided by Fujian Xinsen Carbon Co. Ltd. (China). The activated carbon was outgassed in a vacuum at $383 \mathrm{~K}$ overnight. A desired volume of $\mathrm{H}_{2} \mathrm{IrCl}_{6}$ or $\mathrm{H}_{2} \mathrm{PtCl}_{6}$ (Sino-Platinum Metals Co., Ltd.) aqueous solution $(0.035 \mathrm{~g}$ $\mathrm{L}^{-1}$ ), with nominal Ir or Pt loading of $1 \mathrm{wt} \%$, was added to an aqueous suspension of the activated carbon. The aqueous suspension was subsequently dried at $353 \mathrm{~K}$ for $6 \mathrm{~h}$. The formed catalyst was then reduced by hydrogen with $3 \mathrm{MPa}$ pressure in distilled water at $363 \mathrm{~K}$ for $9 \mathrm{~h}$. Afterward, the $\mathrm{Ir} / \mathrm{C}$ or $\mathrm{Pt} / \mathrm{C}$ catalyst was filtered, rinsed in distilled water until neutral and degassed in a vacuum at $383 \mathrm{~K}$ for $7 \mathrm{~h}$. ICP experiments showed that the actual loadings of Ir and Pt were $0.9985 \%$ and $0.9994 \%$, respectively.

Functionalized ionic liquids catalysts. Type A BFILs SF-A $\left([\mathrm{Hmim}]\left[\mathrm{HSO}_{4}\right]\right)$ was prepared according to the literature ${ }^{36}$ and the synthetic procedure is as follows: $N$-methylimidazole (16.42 $\mathrm{g}, 0.2 \mathrm{~mol}$ ) was placed in a $100 \mathrm{~mL}$ single-necked flask and equi-molar sulfuric acid was added dropwise under vigorous stirring in an ice-water bath. The mixture was then stirred at $T=353 \mathrm{~K}$ for 5 hours. After the reaction was complete, the product was washed with ethyl acetate $(20 \mathrm{~mL} \times 3)$ and diethyl ether $(20 \mathrm{~mL} \times 3)$, respectively, then dried for 6 hours in a vacuum at $353 \mathrm{~K}$. The BFIL SF-A was obtained. SF-B ([Et $\left.{ }_{3}-\mathrm{NH}\right]$ $\left.\left[\mathrm{HSO}_{4}\right]\right)$ and SF-C ([HPy $\left.]\left[\mathrm{HSO}_{4}\right]\right)$ were prepared according to the procedure described above for SF-A with the reaction of triethylamine or pyridine with sulfuric acid (Scheme 2).

The preparation of type B BFILs DF-A ([ $\left.\left.\mathrm{SO}_{3} \mathrm{H}-\mathrm{bmim}\right]\left[\mathrm{HSO}_{4}\right]\right)$ was similar to that used in the literature ${ }^{37}$ and the detailed procedure is as follows: $N$-methylimidazole $(16.42 \mathrm{~g}, 0.2 \mathrm{~mol})$ and equimolar 1,4-butanesultone ( $27.23 \mathrm{~g}, 0.2 \mathrm{~mol})$ were mixed in a $100 \mathrm{~mL}$ single-necked flask. Then, the mixture was stirred at $333 \mathrm{~K}$ under nitrogen until the white solid was completely generated. The solid was washed with ethyl acetate $(20 \mathrm{~mL} \times 3)$ and dried in vacuum at $353 \mathrm{~K}$ for 6 hours. A stoichiometric amount of sulphuric acid was added dropwise to the zwitterion and the mixture was stirred at $353 \mathrm{~K}$ for 6 hours, resulting the formation of DF-A. The product was washed with ethyl acetate $(20 \mathrm{~mL} \times 3)$ and dried under vacuum at $383 \mathrm{~K}$ for 6 hours. DF-B1 $\left(\left[\mathrm{HSO}_{3}-b-\mathrm{N}-\mathrm{Et}_{3}\right]\left[\mathrm{HSO}_{4}\right]\right)$ and $\mathrm{DF}-\mathrm{C}\left(\left[\mathrm{HSO}_{3}-\mathrm{bPy}\right]\left[\mathrm{HSO}_{4}\right]\right)$ were prepared according to the procedure described above for DF-A, with triethylamine and pyridine, respectively, instead of $N$ methylimidazole.

Type C BFILs DF-B2 ([HSO $\left.\left.-b-N-\mathrm{Pr}_{3}\right]\left[\mathrm{HSO}_{4}\right]\right)$ and DF-B3 ( $\left[\mathrm{HSO}_{3}-b-N-\mathrm{Bu}_{3}\right]\left[\mathrm{HSO}_{4}\right]$ ) were prepared using the same procedure describe above, replacing $N$-methylimidazole with tripropylamine and tributylamine. ${ }^{38,39}$

\section{Characterization of catalysts}

TEM and XPS. X-ray Photoelectron Spectroscopy (XPS) was conducted on a Thermo ESCALAB 250 Axis Ultra using monochromatic $\mathrm{Al} \mathrm{K} \alpha$ radiation $(h v=1486.6 \mathrm{eV})$. The binding energies were regulated according to the $\mathrm{C} 1 \mathrm{~s}$ peak at $284.8 \mathrm{eV}$ from the samples.

The particle size of Ir or Pt on the active carbon surface was determined by transmission electron microscopy (TEM) using a Tecnai G2 F30 S-Twin microscope (Philips-FEI Co.). At least 200 individual Ir particles were counted for each catalyst. The Ir or Pt particle size of the catalysts, $d_{\mathrm{s}}$, was calculated using the following equation: $d_{\mathrm{s}}=\sum n_{\mathrm{i}} d_{\mathrm{i}}{ }^{3} / \sum n_{\mathrm{i}} d_{\mathrm{i}}{ }^{2}$, where the visible particle size $d_{\mathrm{i}}$ on the micrographs was measured by a computerized system.

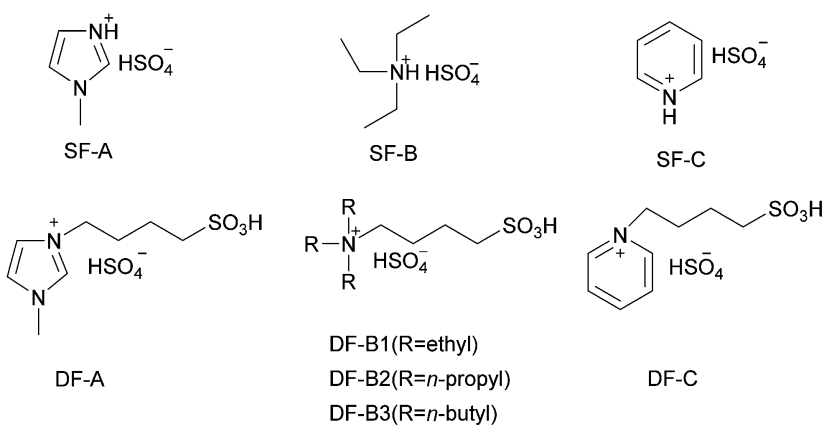

Scheme 2 Structures of the BFILs. 
${ }^{1} \mathrm{H}-\mathrm{NMR}$ and IR spectroscopy of ionic liquids. The structures of BFILs were characterized by ${ }^{1} \mathrm{H}-\mathrm{NMR}$ and IR spectroscopy. Some of the BFILs were further characterized by ${ }^{13} \mathrm{C}-\mathrm{NMR} .{ }^{1} \mathrm{H}-$ NMR and ${ }^{13} \mathrm{C}-\mathrm{NMR}$ spectra were recorded on a Bruker AVANCE III spectrometer in $\mathrm{D}_{2} \mathrm{O}$. FT-IR measurements were performed using $\mathrm{KBr}$ disc on a Nicolet is50 FT-IR infrared spectrometer. The spectral data were obtained as follows and were all in agreement with that reported in the corresponding ref. 27 and 40-42.

Spectral data for SF-A ([Hmim] $\left.]\left[\mathrm{HSO}_{4}\right]\right)$ : ${ }^{1} \mathrm{H}-\mathrm{NMR}(500 \mathrm{MHz}$, $\left.\mathrm{D}_{2} \mathrm{O}\right) \delta 9.06(\mathrm{~s}, 1 \mathrm{H}), 7.70(\mathrm{t}, 1 \mathrm{H}), 7.65(\mathrm{t}, 1 \mathrm{H}), 3.88(\mathrm{~s}, 3 \mathrm{H}) .{ }^{13} \mathrm{C}-$ NMR (125MHZ, $\left.\mathrm{D}_{2} \mathrm{O}\right) \delta 35.86,120.41,122.95,135.86$. IR $\left(\mathrm{cm}^{-1}\right):$ 3149, 2967, 1639, 1586, 1451, 1048, 761.

Spectral data for SF-B $\left(\left[\mathrm{Et}_{3}-\mathrm{NH}\right]\left[\mathrm{HSO}_{4}\right]\right):{ }^{1} \mathrm{H}-\mathrm{NMR}(500 \mathrm{MHz}$, $\left.\mathrm{D}_{2} \mathrm{O}\right) \delta 3.09(\mathrm{q}, 6 \mathrm{H}), 1.18(\mathrm{t}, 9 \mathrm{H}) . \mathrm{IR}\left(\mathrm{cm}^{-1}\right): 2991,2951,1476$, 1399, 1165, 1036.

Spectral data for SF-C ([HPy $\left.]\left[\mathrm{HSO}_{4}\right]\right)$ : ${ }^{1} \mathrm{H}-\mathrm{NMR}(500 \mathrm{MHz}$, $\left.\mathrm{D}_{2} \mathrm{O}\right) \delta 8.66(\mathrm{~d}, 2 \mathrm{H}), 8.50(\mathrm{~m}, 1 \mathrm{H}), 8.08-7.84(\mathrm{~m}, 2 \mathrm{H}) . \mathrm{IR}\left(\mathrm{cm}^{-1}\right)$ : 3071, 1639, 1545, 1488.

Spectral data for DF-A ([SO $\left.3 \mathrm{H}-\mathrm{bmim}]\left[\mathrm{HSO}_{4}\right]\right):{ }^{1} \mathrm{H}-\mathrm{NMR}(500$ $\left.\mathrm{MHz}, \mathrm{D}_{2} \mathrm{O}\right) \delta 8.59(\mathrm{~s}, 1 \mathrm{H}), 7.32(\mathrm{~m}, 2 \mathrm{H}), 4.10(\mathrm{t}, 2 \mathrm{H}), 3.80-3.72(\mathrm{~m}$, $3 \mathrm{H}), 2.83-2.62(\mathrm{~m}, 2 \mathrm{H}), 1.88(\mathrm{~m}, 2 \mathrm{H}), 1.76-1.41(\mathrm{~m}, 2 \mathrm{H}) .{ }^{13} \mathrm{C}-$ NMR (125 MHz, $\left.\mathrm{D}_{2} \mathrm{O}\right) \delta$ 21.50, 28.43, 35.87, 49.28, 51.07, 122.64, 123.55, 136.56. IR ( $\left.\mathrm{cm}^{-1}\right): 3156,3115,2960,1575,1169$, 1031, 794, 747, 579.

Spectral data for DF-B1 ([HSO $\left.\left.{ }_{3}-b-N-\mathrm{Et}_{3}\right]\left[\mathrm{HSO}_{4}\right]\right):{ }^{1} \mathrm{H}-\mathrm{NMR}(500$ $\left.\mathrm{MHz}, \mathrm{D}_{2} \mathrm{O}\right) \delta 3.08$ (q, 6H), 2.99 (dd, 2H), 2.76 (dd, 2H), 1.76-1.52 $(\mathrm{m}, 4 \mathrm{H}), 1.06$ (t, 9H). ${ }^{13} \mathrm{C}-\mathrm{NMR}\left(125 \mathrm{MHz}, \mathrm{D}_{2} \mathrm{O}\right) \delta 7.36,19.98$, 21.90, 50.26, 52.28, 56.10. IR ( $\left.\mathrm{cm}^{-1}\right): 2991,1488,1396,1189$, $730,587$.

Spectral data for DF-B2 ([HSO $\left.\left.-b-N-\mathrm{Pr}_{3}\right]\left[\mathrm{HSO}_{4}\right]\right):{ }^{1} \mathrm{HNMR}(500$ $\mathrm{MHz}, \mathrm{D}_{2} \mathrm{O}$ ) $\delta 3.19-3.08(\mathrm{~m}, 2 \mathrm{H}), 3.07-2.98(\mathrm{~m}, 6 \mathrm{H}), 2.88-2.74(\mathrm{~m}$, $2 \mathrm{H}), 1.77-1.67(\mathrm{~m}, 2 \mathrm{H}), 1.64(\mathrm{dd}, 2 \mathrm{H}), 1.61-1.46(\mathrm{~m}, 6 \mathrm{H}), 0.80(\mathrm{t}$, 9H). IR ( $\left.\mathrm{cm}^{-1}\right)$ : 2976, 2884, 1487, 1473, 1169, 1054, 720, 579.

Spectral data for DF-B3 ([HSO $\left.\left.-b-N-\mathrm{Bu}_{3}\right]\left[\mathrm{HSO}_{4}\right]\right)$ : ${ }^{1} \mathrm{H}$ NMR (500 MHz, $\left.\mathrm{D}_{2} \mathrm{O}\right) \delta 3.01-2.89(\mathrm{~m}, 6 \mathrm{H}), 2.89-2.80(\mathrm{~m}, 2 \mathrm{H}), 2.71-$ 2.60 (m, 2H), 1.60-1.45 (m, 4H), 1.43-1.32 (m, 6H), 1.15-1.02 $(\mathrm{m}, 6 \mathrm{H}), 0.66$ (q, 9H). IR ( $\left.\mathrm{cm}^{-1}\right): 2963,2876,1472,1168,1054$, 726, 579.

Spectral data for DF-C ([HSO $\left.\left.{ }_{3}-\mathrm{bPy}\right]\left[\mathrm{HSO}_{4}\right]\right)$ : ${ }^{1} \mathrm{H}-\mathrm{NMR}(500$ $\left.\mathrm{MHz}, \mathrm{D}_{2} \mathrm{O}\right) \delta 8.73(\mathrm{~d}, 2 \mathrm{H}), 8.42(\mathrm{~m}, 1 \mathrm{H}), 7.95(\mathrm{t}, 2 \mathrm{H}), 4.53(\mathrm{t}, 2 \mathrm{H})$, 2.95-2.72 (m, 2H), 2.15-1.86 (m, 2H), $1.75-1.42(\mathrm{~m}, 2 \mathrm{H}) .{ }^{13} \mathrm{C}-$ NMR (125 MHz, $\left.\mathrm{D}_{2} \mathrm{O}\right) \delta$ 20.92, 29.56, 49.92, 61.28, 128.58, 144.38, 146.10. IR $\left(\mathrm{cm}^{-1}\right): 3070,2949,1635,1489,1456,1173$, 728,579 .

\section{Acidity of ionic liquids}

In order to explore the relationship between the catalytic performance and the acidity of BFILs, the acidity of BFILs was measured by an acid-base titration method. ${ }^{43}$ Phenolphthalein was used as an indicator, and the concentration of $\mathrm{NaOH}$ aqueous solution was $2 \mathrm{~mol} \mathrm{~L}^{-1}$.

$$
\text { Acidity }=\frac{n(\mathrm{NaOH})}{n(\text { BFILs })}
$$

\section{Solubility of NB in the reaction solution}

The solubility of NB in the reaction solution was checked by HPLC, which was similar to that used in the literature. ${ }^{44}$ The method is as follows: the slight excess of 6 NB was sonicated in an ultrasonic washer for 30 minutes and then stirred at $353 \mathrm{~K}$ for 5 hours. After that, $1 \mathrm{~mL}$ of the upper homogeneous was transferred to the ethanol solution and diluted to a fixed volume, then determined by HPLC.

\section{Evaluation of catalyst}

This reaction was carried out in a $75 \mathrm{~mL}$ stainless steel autoclave (Parr MRS5000). In a typical experiment, NB, catalyst, BFILs or $10 \%$ sulphuric acid solution and CTAB were introduced into the autoclave. After the air in the reactor was replaced with nitrogen and hydrogen, three times, respectively, the reactions were performed at $0.8 \mathrm{MPa} \mathrm{H}_{2}, 353 \mathrm{~K}$, the optimal reaction conditions that were previously determined. The final products were analysed by HPLC on an Agilent 1260 (column Agilent TC-C18, 5 $\mu \mathrm{m})$ system with $\mathrm{UV}$ detector $(\lambda=254 \mathrm{~nm})$. The column temperature was $298 \mathrm{~K} . \mathrm{CH}_{3} \mathrm{CN} / \mathrm{H}_{2} \mathrm{O}(70 / 30, \mathrm{v} / \mathrm{v})$ was used as the mobile phase and the flow rate was $1 \mathrm{~mL} \mathrm{~min}^{-1}$.

\section{Recycling of Ir/C and ionic liquids}

The Ir/C catalyst in the system was separated by vacuum filtration, and the aniline by-product was separated by ordinary extraction. After most of the water was removed by distillation under reduced pressure, PAP precipitated in the ice-water bath, due to its low solubility in aqueous solution. The remaining BFILs could then be reused..$^{35}$

\section{Results and discussion}

\section{Hydrogenation catalyst}

In our previous study of the hydrogenation of halogenated nitrobenzene, we had compared the catalytic performance of the $\mathrm{Ir} / \mathrm{C}$ and the $\mathrm{Pd} / \mathrm{C}$ catalysts. ${ }^{13}$ DFT calculations showed that adsorption properties of halogenated nitrobenzene on the Ir surface were different from that on the Pd surface. The distance between oxygen and Ir was much shorter than that between oxygen and Pd. Moreover, in our study of the hydrogenation of NB to AN, we also found that the amount of PHA intermediate detected in the solution of the $\mathrm{Ir} / \mathrm{C}$ catalyst was much larger than that of the $\mathrm{Pd} / \mathrm{C}$ catalyst. The adsorption properties of halogenated nitrobenzene on Ir aroused our interest. As we all know, for the hydrogenation of NB to PAP, NB was first hydrogenated to the PHA intermediate and then the PHA intermediate was desorbed from the surface of the hydrogenation catalyst and converted to PAP through the acidcatalysed Bamberger rearrangement. Therefore, the desorption properties of the PHA intermediate from the hydrogenation catalyst directly determined the amount of PHA involved in the next Bamberger rearrangement. Considering the above results, we conceived of Ir as the hydrogenation catalyst for the one-pot hydrogenation of NB to PAP. Thus, we first compared the catalytic performance of Ir with the traditional Pt catalyst.

The XPS spectra of Ir/C and Pt/C are shown in Fig. 1. The Ir $4 \mathrm{f}_{7 / 2}$ could be deconvoluted into two peaks at about $61.1 \mathrm{eV}$ and 

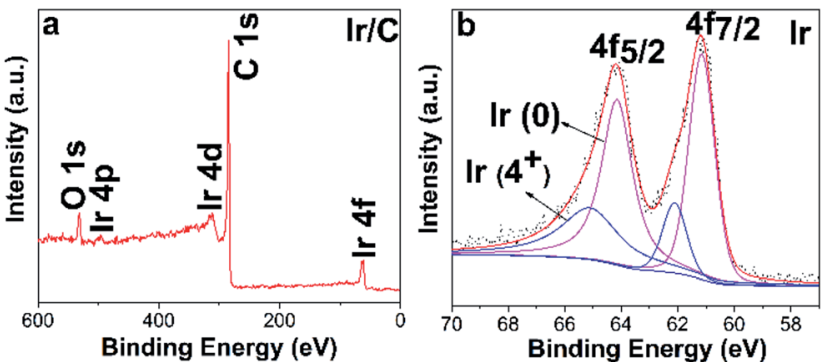
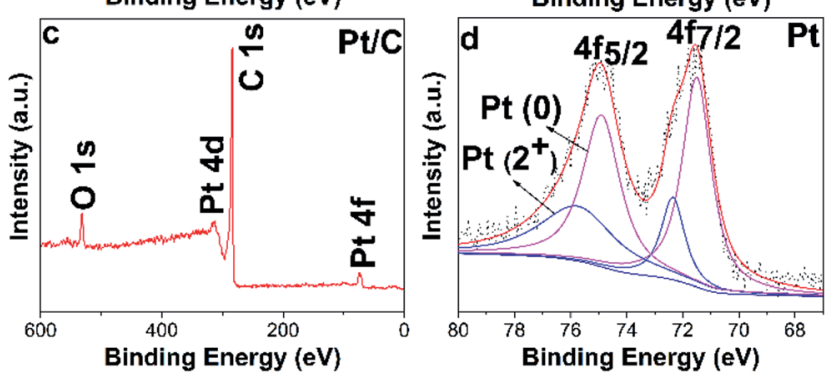

Fig. $1 \mathrm{Ir} / \mathrm{C}(\mathrm{Pt} / \mathrm{C})$ XPS spectra of the survey scan $(\mathrm{a}, \mathrm{C})$, and $\operatorname{Ir}(\mathrm{Pt}) 4 \mathrm{f}$ high-resolution XPS spectra of $\mathrm{Ir} / \mathrm{C}(\mathrm{Pt} / \mathrm{C})(\mathrm{b}, \mathrm{d})$.

$62.2 \mathrm{eV}$, which were assigned to metallic $\operatorname{Ir}(0)$ and $\operatorname{Ir}\left(4^{+}\right)$ respectively. ${ }^{45,46}$ The $\mathrm{Pt} 4 \mathrm{f}_{7 / 2}$ could be deconvoluted into two peaks at about $71.5 \mathrm{eV}$ and $72.3 \mathrm{eV}$, which were assigned to metallic $\operatorname{Pt}(0)$ and $\operatorname{Pt}\left(2^{+}\right)$respectively. ${ }^{47,48}$ The presence of $\operatorname{Ir}\left(4^{+}\right)$ and $\operatorname{Pt}\left(2^{+}\right)$might be related to the oxidation of Ir and Pt particles in air. ${ }^{46}$

High resolution transmission electron microscopy (HRTEM) images (Fig. 2a, b, e and f) revealed that $\operatorname{Ir}(\mathrm{Pt})$ particles were found on the surface of the activated carbon support. Moreover, the hydrogenation of NB to PAP did not cause any appreciable changes in the catalysts. At the same time, transmission electron microscopy (TEM) images and particle size distribution of the $\operatorname{Ir}(\mathrm{Pt}$ ) particles (Fig. 2c and d) demonstrated that the surface of metal particles were in a small and uniform state and the average particle size of the Ir/C catalyst was very close to that of the $\mathrm{Pt} / \mathrm{C}$ catalyst. All these results indicated that the Ir and Pt should have similar amounts of active sites under the same metal load.

The hydrogen consumption rates for the hydrogenation of NB to AN were then studied and the results are shown in Fig. 3, where we can easily find that the hydrogen consumption rate of the $\mathrm{Pt} / \mathrm{C}$ catalyst was much higher than that of the Ir/C catalyst. Obviously, this significant difference in the hydrogenation rate was not caused by the number of metal active sites. In order to find out the reason, the product distribution of the $\mathrm{Pt} / \mathrm{C}$ catalyst for hydrogenation of NB to AN was then investigated and the results were demonstrated in Fig. 4. Compared to our previous study results, ${ }^{13}$ we found that the amount of the PHA intermediate distribution of $\mathrm{Pt} / \mathrm{C}$ was much lower than that of Ir/C (about $21 \%)$. This indicated that the PHA intermediate desorbed more easily from the Ir surface than from the Pt surface. The more easily PHA was desorbed from the metal surface, the less PHA was left on the metal surface to be further hydrogenated to AN, which should be the main reason why the hydrogen consumption rate of Ir/C was much lower than that of Pt/C.

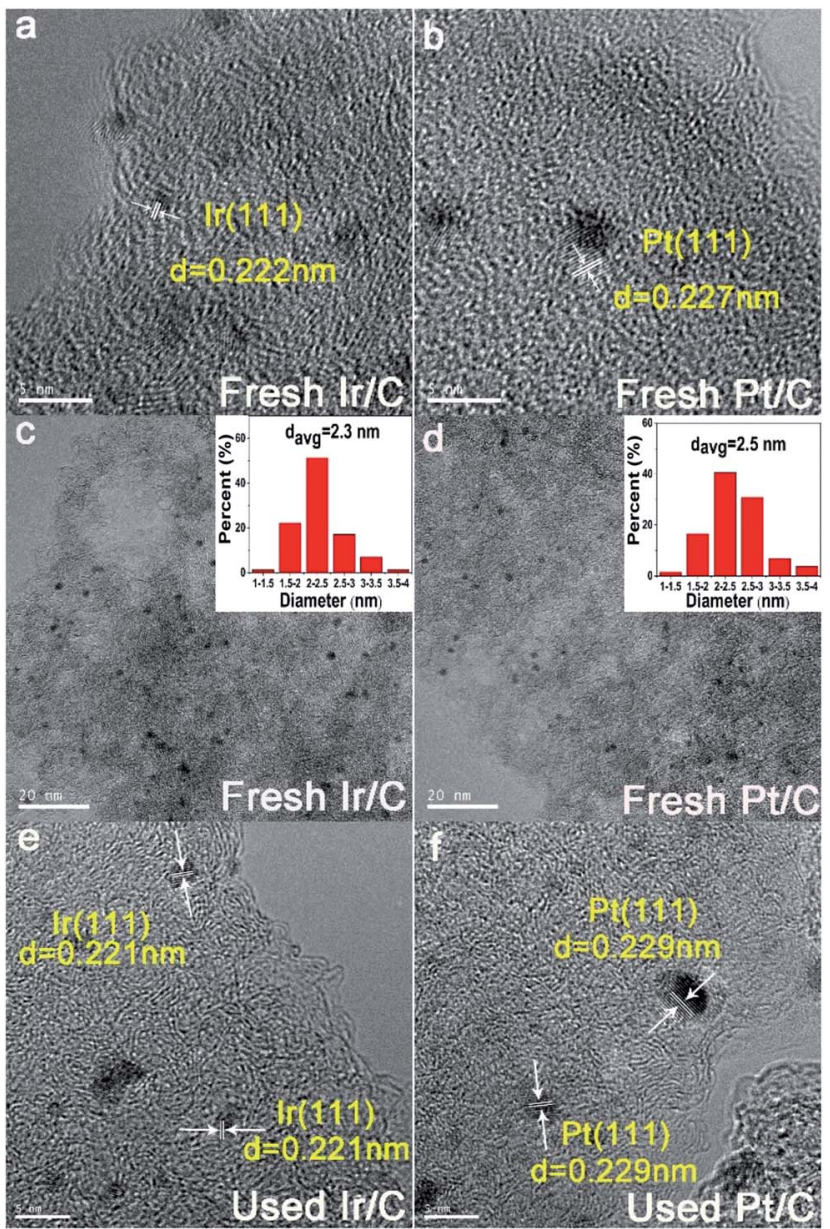

Fig. $2 \operatorname{HR}-\operatorname{TEM}(a, b, e, f)$ images, TEM images (c, d) and particle size distribution (c, d) of fresh and used $\mathrm{Ir} / \mathrm{C}$ and $\mathrm{Pt} / \mathrm{C}$ catalysts.

As an intermediate of the hydrogenation of NB to PAP, the distinct adsorption properties of PHA on different metal catalysts could not only affect the hydrogen consumption rate, but also influence the PAP selectivity. Fig. 3 showed the hydrogen consumption rate of the hydrogenation of NB to PAP. As we had speculated, the hydrogen consumption rate of Ir and Pt catalysts all decreased sharply, compared to the hydrogenation of $\mathrm{NB}$ to $\mathrm{AN}$, and the hydrogen consumption rate of the $\mathrm{Ir} / \mathrm{C}$ catalyst was still much lower than that of the Pt/C. On the other hand, we further studied the catalytic performance of Ir/C and $\mathrm{Pt} / \mathrm{C}$ for the hydrogenation of NB to PAP (Table 1). Our results indicated that the PAP selectivity of the Ir/C catalyst was significantly higher than that of the $\mathrm{Pt} / \mathrm{C}$ catalyst. We thought the reason was that the easier desorption of PHA from Ir allowed more PHA to be involved in the following Bamberger rearrangement, which led to the lower hydrogen consumption rate and higher selectivity of PAP. Thus, we concluded that Ir was more suitable than Pt for the hydrogenation of NB to PAP.

\section{Brpnsted acid functionalized ionic liquids}

When the hydrogenation catalyst was determined, we selected BFILs as acid catalysts and constructed a new catalytic system 


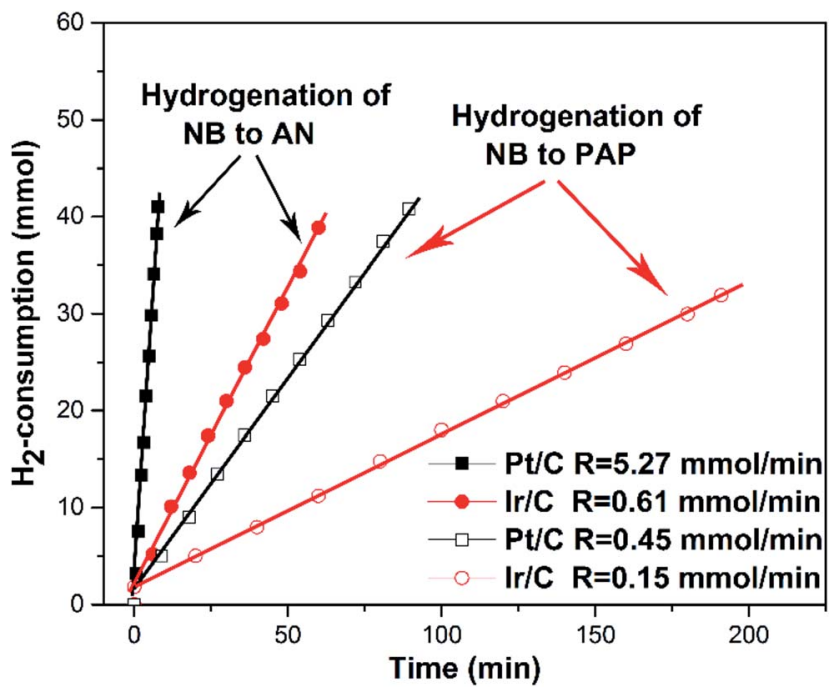

Fig. 3 Hydrogen consumption rate of the $\mathrm{Ir} / \mathrm{C}$ and Pt/C catalysts for the hydrogenation of $N B$ to $A N^{a}$ and hydrogenation of NB to PAP Reaction conditions: (a) $0.02 \mathrm{~mol}$ of NB, $0.1 \mathrm{~g}$ of catalyst, $25 \mathrm{~mL}$ of ethanol, $P_{\mathrm{H}_{2}}=1.0 \mathrm{MPa}, T=353 \mathrm{~K}$, stirring rate $=1200 \mathrm{rpm}$. (b) $0.02 \mathrm{~mol}$ of NB, $0.1 \mathrm{~g}$ of catalyst, $25 \mathrm{~mL}$ of $10 \%$ sulphuric acid solution, $0.025 \mathrm{~g}$ of CTAB, $P_{\mathrm{H}_{2}}=0.8 \mathrm{MPa}, T=353 \mathrm{~K}$, stirring rate $=1000 \mathrm{rpm}$.

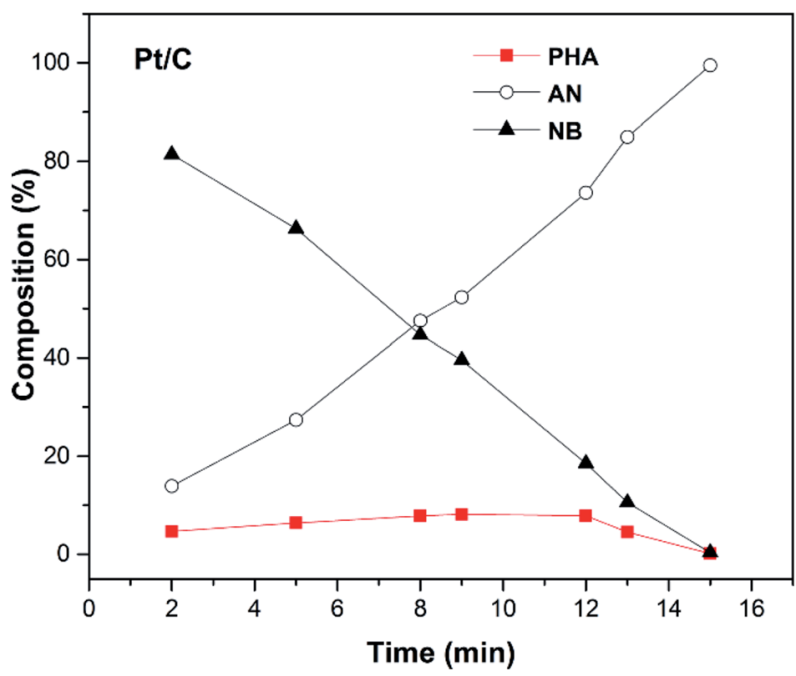

Fig. 4 Product distribution of catalytic hydrogenation of NB to AN on the $\mathrm{Pt} / \mathrm{C}$ catalyst. Reaction conditions: $0.05 \mathrm{~g}$ of catalyst, $25 \mathrm{~mL}$ of ethanol, $0.02 \mathrm{~mol}$ of $\mathrm{NB}, P_{\mathrm{H}_{2}}=1.0 \mathrm{MPa} ; T=353 \mathrm{~K}$, stirring rate $=$ $1200 \mathrm{rpm}$.

Table 1 Catalytic performance of $\mathrm{Pt} / \mathrm{C}$ and $\mathrm{Ir} / \mathrm{C}^{a}$

\begin{tabular}{llll}
\hline & & \multicolumn{2}{l}{ Selectivity (\%) } \\
\cline { 3 - 4 } Catalyst & Conversion & PAP & AN \\
\hline $1 \% \mathrm{Pt} / \mathrm{C}$ & 100 & 40.5 & 59.5 \\
$1 \% \mathrm{Ir} / \mathrm{C}$ & 100 & 60.4 & 39.5
\end{tabular}

${ }^{a}$ Reaction conditions: $0.1 \mathrm{~g}$ of catalyst, $25 \mathrm{~mL}$ of $10 \%$ sulphuric acid solution, $0.02 \mathrm{~mol}$ of NB, $0.025 \mathrm{~g}$ of CTAB, $P_{\mathrm{H}_{2}}=0.8 \mathrm{MPa}, T=353 \mathrm{~K}$, stirring rate $=1000 \mathrm{rpm}$. with Ir/C for the hydrogenation of NB to PAP. In this regard, three types of BFILs were synthesized. The type A BFILs (SF-A, SF-B and SF-C) were single functionalized ionic liquids, which were characterized by the bisulfate ion as the anion and $N$ methylimidazole, triethylamine or pyridine as the cations, respectively. Based on the preparation of type A BFILs, type B BFILs (DF-A, DF-B1 and DF-C) were designed with butyl sulfonic acid functionalized to the $\mathrm{N}$ atom. The purpose of this reform was to increase the acid strength of the corresponding BFILs. In order to enhance the lipophilicity of DF-B1, type C BFILs (DF-B2 and DF-B3) were then prepared by replacing the ethyl group in DF-B1 with $n$-propyl (DF-B2) or $n$-butyl (DF-B3) respectively. Type C BFILs were more targeted to functionalization, compared to DF-B1. They were a type of dually functionalized ionic liquid and were expected to be used as acid catalyst and surfactant at the same time.

The hydrogen consumption rates in the BFILs were firstly investigated in the presence of surfactant. As shown in Fig. 5, the hydrogen consumption rates in type A and type B BFILs were different. We could easily see that the hydrogen consumption rate in type A BFILs was much higher than that in type B BFILs. The hydrogen consumption rates in DF-A, DF-B1 and DF-C were basically within the same range. The above experimental results could be explained through the mechanism of the hydrogenation of NB to PAP. This reaction involved two competitive parallel reactions, and the acidity of BFILs affects the trend of the Bamberger rearrangement reaction. When the acidity of BFILs was stronger, the Bamberger rearrangement was dominant in the parallel reaction and the over hydrogenation side reaction was inhibited, which led to the lower hydrogen consumption rate. The acidity of type B BFILs stemmed not only from the bisulfate anion, but also the sulfonic acid, which made them more acidic than type A BFILs and resulted in the lower hydrogen consumption rate.

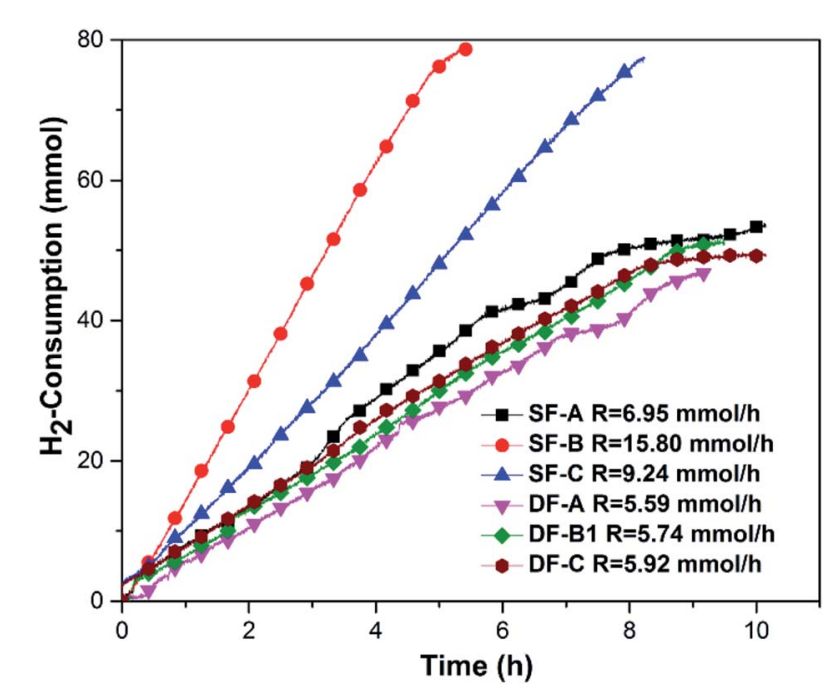

Fig. 5 The hydrogen consumption rate of the reaction in different BFILs in the presence of CTAB. Reaction conditions: $0.02 \mathrm{~mol}$ of NB, $25 \mathrm{~mL}$ of $\mathrm{H}_{2} \mathrm{O}, 0.1 \mathrm{~g}$ of $\mathrm{Ir} / \mathrm{C}, 0.025 \mathrm{~g}$ of CTAB, $353 \mathrm{~K}, 0.8 \mathrm{MPa}, 1000 \mathrm{rpm}$, 0.05 mol BFILs of type A, 0.025 mol BFILs of type B. 
Considering the influence of the acidity on the Bamberger rearrangement reaction, we thought that it was necessary to further compare the acidity of the different BFILs quantitatively. Therefore, the acidity of the BFILs was quantitatively tested by sodium hydroxide titration. The relationship between the amount of acid and the catalytic performance of different kinds of BFILs was studied. The results are presented in Table 2, where it can be seen that the selectivity of PAP was proportional to the acidity of BFILs. The strong acidity of BFILs benefited the Bamberger rearrangement to form PAP and thus increased the selectivity of PAP; the relative acidity of the $\mathrm{SO}_{3} \mathrm{H}$-functionalized ILs was stronger than that of the anion-functionalized $\operatorname{ILs}^{33}$ and thus, the type B BFILs should possess stronger acidity than that of the type A BFILs. Due to the acidity of type A BFILs being much weaker than that of type $B$, there was an obvious gap in the PAP selectivity between type A and type B BFILs. We could also see that the PAP selectivity in type B BFILs were very close to that in sulfuric acid. Among all the BFILs of type B, DF-A showed the best catalytic performance and the PAP selectivity of DF-A was even higher than that of sulfuric acid. We thought that this reason could be attributed to its weak steric hindrance ${ }^{49}$ and strong acidity. Our results indicate that BFILs could already replace sulfuric acid for the hydrogenation of NB to PAP in the presence of surfactant.

Due to the lower solubility of NB in the reaction solution, surfactant must be added for the hydrogenation of NB to PAP. The addition of surfactant led to some problems such as a complicated system and troublesome operation. Considering the properties of the BFILs, we further explored the catalytic performance of different BFILs without the existence of surfactant. The result is shown in Table 3. As we predicted, the PAP selectivity greatly decreased both the type B BFILs and sulfuric acid, implying the non-negligible importance of surfactant for such a complex reaction system. However, the catalytic performance of DF-B1 caught our attention. Although DF-B1 was the weakest acid among all the type B BFILs, it showed the highest PAP selectivity without the existence of surfactant. We speculated that the catalytic performance of the BFILs was also related to lipophilicity in addition to acidity. The lipophilicity of the BFILs increased the solubility of the reactants, which would make the reaction occur more easily. This provided us with a good idea for modifying the DF-B1. In order

Table 2 Catalytic performance of BFILs with surfactant ${ }^{a}$

\begin{tabular}{lllllll}
\hline & & Amount of & & \multicolumn{2}{c}{$\begin{array}{l}\text { Conversion } \\
\text { (\%) }\end{array}$} & \multicolumn{2}{c}{ Selectivity (\%) } \\
\cline { 5 - 6 } & BFILs & acid & 100 & PAP & AN \\
\hline \multirow{2}{*}{ Type A } & SF-A & 1.65 & 100 & 51.2 & 48.8 \\
& SF-B & 0.83 & 100 & 29.3 & 70.7 \\
& SF-C & 1.06 & 100 & 32.7 & 67.3 \\
Type B & DF-A & 1.94 & 100 & 62.4 & 37.6 \\
& DF-B1 & 1.73 & 100 & 56.4 & 43.6 \\
& DF-C & 1.85 & 100 & 56.9 & 43.1
\end{tabular}

${ }^{a}$ Reaction conditions: $0.02 \mathrm{~mol}$ of $\mathrm{NB}, 25 \mathrm{~mL}$ of $\mathrm{H}_{2} \mathrm{O}, 0.1 \mathrm{~g}$ of $\mathrm{Ir} / \mathrm{C}$, $0.025 \mathrm{~g}$ of CTAB, $353 \mathrm{~K}, 0.8 \mathrm{MPa}, 1000 \mathrm{rpm}, 0.05 \mathrm{~mol}$ of type A, $0.025 \mathrm{~mol}$ of type B.
Table 3 Catalytic performance of BFILs without surfactant ${ }^{a}$

\begin{tabular}{lllllll}
\hline & & & & \multicolumn{2}{c}{ Selectivity (\%) } \\
\cline { 5 - 6 } & BFILs & $\begin{array}{l}\text { Solubility } \\
\left(\mathrm{g} \mathrm{L}^{-1}\right)\end{array}$ & $\begin{array}{l}\text { Conversion } \\
(\%)\end{array}$ & PAP & AN \\
\hline $\mathrm{H}_{2} \mathrm{SO}_{4}$ & - & - & 100 & 43.9 & 56.1 \\
Type B & DF-A & 3.1 & 100 & 32.6 & 67.4 \\
& DF-B1 & 3.4 & 100 & 37.8 & 62.2 \\
& DF-C & 2.8 & 100 & 30.8 & 69.2 \\
Type C & DF-B2 & 7.6 & 100 & 44.3 & 55.7 \\
& DF-B3 & 11.5 & 100 & 50.8 & 49.2
\end{tabular}

${ }^{a}$ Reaction conditions: $0.02 \mathrm{~mol} \mathrm{NB}, 0.025 \mathrm{~mol}$ BFILs, $25 \mathrm{~mL}$ of $\mathrm{H}_{2} \mathrm{O}$, $0.1 \mathrm{~g}$ of $\mathrm{Ir} / \mathrm{C}, 353 \mathrm{~K}, 0.8 \mathrm{MPa}, 1000 \mathrm{rpm}$.

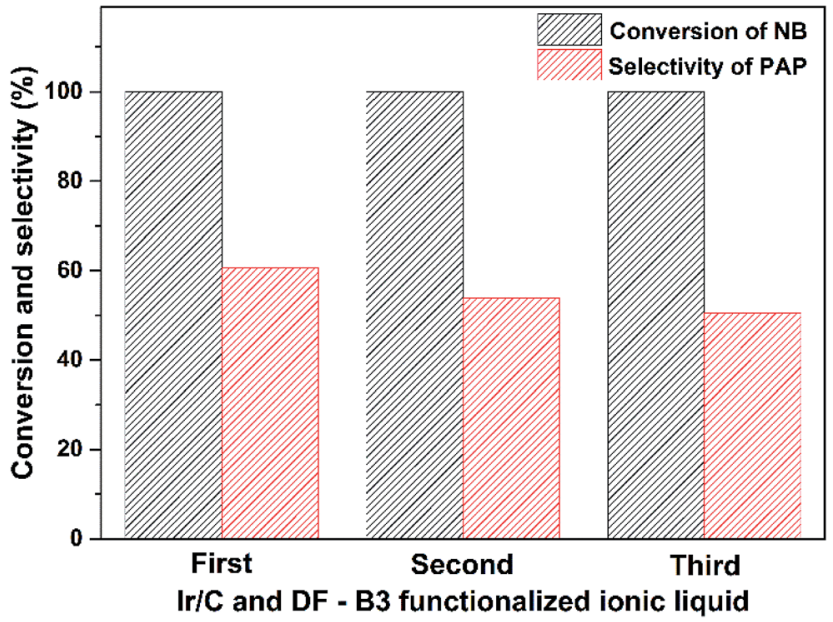

Fig. 6 Recycling experiments of Ir/C and DF-B3 for hydrogenation of NB to PAP. Reaction conditions: $0.02 \mathrm{~mol}$ of NB, $0.025 \mathrm{~mol}$ of DF-B3, $25 \mathrm{~mL}$ of $\mathrm{H}_{2} \mathrm{O}, 0.1 \mathrm{~g}$ of $\mathrm{Ir} / \mathrm{C}, 353 \mathrm{~K}, 0.8 \mathrm{MPa}, 1000 \mathrm{rpm}$

to further enhance the lipophilicity of DF-B1, we increased the length of the carbon chain connected to the $\mathrm{N}$ atom by replacing the ethyl group in DF-B1 with the $n$-propyl or $n$-butyl carbon chain. As expected, the solubility of NB in type C BFILs improved significantly, and the selectivity of PAP increased with the elongation of the carbon chain. DF-B3 showed the best catalytic performance with $50.8 \%$ selectivity of PAP. Our results indicated that the DF-B3 dually functionalized ionic liquid could simultaneously be used as an acid catalyst and surfactant for the hydrogenation of NB to PAP.

Recyclability is one of the important properties of catalysts. Herein, we chose the catalytic system composed of Ir/C and DFB3 to conduct the recycling experiments. As shown the Fig. 6, the conversion of NB remained stable and the selectivity of PAP decreased slightly after being recycled three times. This indicated that the new catalytic system of Ir/C and DF-B3 had good stability in the hydrogenation of NB to PAP.

\section{Conclusions}

The desorption properties of the PHA intermediate from the hydrogenation metal catalyst and the acidity of the acid catalyst 
were the key factors in the one-pot hydrogenation of NB to PAP. Our work included the following two aspects: the PHA intermediate was more easily desorbed from the surface of the Ir catalyst, compared to the traditional Pt catalyst; the BFILs with bisulfate ion and sulfonic acid exhibited similar acidity to sulfuric acid. A new catalyst system was constructed through the combination of Ir/C and BFILs and applied to the catalysis of the one-pot hydrogenation of NB to PAP. Our results indicate that the PAP selectivity of $\mathrm{Ir} / \mathrm{C}$ and $\left[\mathrm{SO}_{3} \mathrm{H}-\mathrm{bmim}\right]\left[\mathrm{HSO}_{4}\right]$ was far greater than that of $\mathrm{Pt} / \mathrm{C}$ and sulfuric acid. In addition, we found that the dually functionalized ionic liquid ([ $\left.\mathrm{HSO}_{3}-b-N-\mathrm{Bu}_{3}\right]$ $\left.\left[\mathrm{HSO}_{4}\right]\right)$ could be used simultaneously as acid catalyst and surfactant, due to its higher lipophilicity. Therefore, the great catalytic performance of the Ir/C and BFILs system could open new ground for the study of the catalyzed hydrogenation of NB to PAP.

\section{Acknowledgements}

This work is financially supported by National Natural Science Foundation of China (Grant No. 21473159, 21476208) and Natural Science Foundation of Zhejiang Province (LY17B060008).

\section{Notes and references}

1 K. I. Min, J. S. Choi, Y. M. Chung, W. S. Ahn, R. Ryoo and P. K. Lim, Appl. Catal., A, 2008, 337, 97-104.

2 C. V. Rode, M. J. Vaidya, R. Jaganathan and R. V. Chaudhari, Chem. Eng. Sci., 2001, 56, 1299-1304.

3 Z. Dong, T. Wang, J. Zhao, T. Fu, X. Guo, L. Peng, B. Zhao, N. Xue, W. Ding and Z. Xie, Appl. Catal., A, 2016, 520, 151156.

4 M. Blosi, S. Albonetti, A. L. Costa, N. Sangiorgi and A. Sanson, Chem. Eng. J., 2013, 215-216, 616-625.

5 Z. Ma, L. Zhang, R. Chen, W. Xing and N. Xu, Chem. Eng. J., 2008, 138, 517-522.

6 M. A. Bhosale, D. R. Chenna, J. P. Ahire and B. M. Bhanage, $R S C$ Adv., 2015, 5, 52817-52823.

7 E. A. Braude, Nature, 1952, 169, 80.

8 S. K. Tanielyan, J. J. Nair, N. Marin, G. Alvez, R. J. McNair, D. Wang and R. L. Augustine, Org. Process Res. Dev., 2007, 11, 681-688.

9 Y. Gao, F. Wang, S. Liao and D. Yu, React. Kinet. Catal. Lett., 1998, 64, 351-357.

10 B. Zhang, Y. Yuan, K. Philippot and N. Yan, Catal. Sci. Technol., 2015, 5, 1683-1692.

11 J. Li, R. R. Nasaruddin, Y. Feng, J. Yang, N. Yan and J. Xie, Chem.-Eur. J., 2016, 22, 14816-14820.

12 B. Zhang, H. Asakura, J. Zhang, J. Zhang, S. De and N. Yan, Angew. Chem., Int. Ed., 2016, 55, 8319-8323.

13 L. Ma, J. Wang, H. Wang, Q. Zhang, C. Lu, X. He and X. Li, Chin. J. Chem. Eng., 2017, 25, 306-312.

14 G. Quartarone, L. Ronchin, A. Tosetto and A. Vavasori, Appl. Catal., A, 2014, 475, 169-178.

15 S. Liu, Y. Hao and J. Jiang, Ind. Eng. Chem. Res., 2014, 53, 8372-8375.
16 S. Wang, Y. Ma, Y. Wang, W. Xue and X. Zhao, J. Chem. Technol. Biotechnol., 2008, 83, 1466-1471.

17 S. Wang, Y. Wang, Y. Gao and X. Zhao, Chin. J. Catal., 2010, 31, 637-644.

18 S. Wang, Y. Jin, B. He, Y. Wang and X. Zhao, Sci. China: Chem., 2010, 53, 1514-1519.

19 P. Liu, Y. Hu, M. Ni, K. You and H. Luo, Catal. Lett., 2010, 140, 65-68.

20 A. Deshpande, F. Figueras, M. L. Kantam, K. J. Ratnam, R. S. Reddy and N. S. Sekhar, J. Catal., 2010, 275, 250-256.

21 Y. Liu, Y. Fang, X. Lu, Z. Wei and X. Li, Chem. Eng. J., 2013, 229, 105-110.

22 T. Zhang, J. Jiang and Y. Wang, Org. Process Res. Dev., 2015, 19, 2050-2054.

23 T. Komatsu and T. Hirose, Appl. Catal., A, 2004, 276, 95-102. 24 X. Liu, M. Liu, X. Guo and J. Zhou, Catal. Commun., 2008, 9, 1-7.

25 K. L. Toews, R. M. Shroll, C. M. Wai and N. G. Smart, Anal. Chem., 2002, 67, 4040-4043.

26 E. Rafiee and F. Mirnezami, J. Mol. Struct., 2017, 1130, 296302.

27 J. Lunagariya, A. Dhar and R. L. Vekariya, RSC Adv., 2017, 7, 5412-5420.

28 Y. Liu, W. Xiao, S. Xia and P. Ma, Carbohydr. Polym., 2013, 92, 218-222.

29 F. Parveen, K. Gupta and S. Upadhyayula, Carbohydr. Polym., 2017, 159, 146-151.

30 H. Wang, X. Meng, G. Zhao and S. Zhang, Green Chem., 2017, 19, 1462-1489.

31 P. Gan and S. Tang, Chin. J. Chem. Eng., 2016, 24, 1497-1504.

32 A. G. Khiratkar, P. N. Muskawar and P. R. Bhagat, RSC Adv., 2016, 6, 105087-105093.

33 N. Yan, Y. Yuan, R. Dykeman, Y. Kou and P. J. Dyson, Angew. Chem., Int. Ed. Engl., 2010, 49, 5549-5553.

34 R. Kore and R. Srivastava, J. Mol. Catal. A: Chem., 2013, 376, 90-97.

35 Y. Cui, D. Yuan, Y. Wang and X. Zhao, J. Ind. Eng. Chem., 2009, 60, 345-350.

36 J. Weng, C. Wang, H. Li and Y. Wang, Green Chem., 2006, 8, 96-99.

37 J. Sun, H. Li, H. Song, Q. Wu, Y. Zhao and Q. Jiao, RSC Adv., 2015, 5, 87200-87205.

38 D. Fang, X. L. Zhou, A. Zhiwen Ye and Z. L. Liu, Ind. Eng. Chem. Res., 2006, 45, 7982-7984.

39 S. Liu, X. Liu and C. Wang, Ind. Eng. Chem. Res., 2013, 52, 16719-16723.

40 Y. Zhao, J. Long, F. Deng, X. Liu, Z. Li, C. Xia and J. Peng, Catal. Commun., 2009, 10, 732-736.

41 D. Fang, Q. R. Shi, J. Cheng, K. Gong and Z. L. Liu, Appl. Catal., A, 2008, 345, 158-163.

42 J. Gui, X. Cong, D. Liu, X. Zhang, Z. Hu and Z. Sun, Catal. Commun., 2004, 5, 473-477.

43 X. L. Zhang, H. L. An, H. Q. Zhang, X. Q. Zhao and Y. J. Wang, Ind. Eng. Chem. Res., 2014, 53, 16707-16714.

44 F. Yu, G. Liu, E. Liang, C. Gao and W. Zhong, Mil. Med. Sci., 2012, 36, 49-55. 
45 L. Yuan, Z. Yan, L. Jiang, E. Wang, S. Wang and G. Sun, J. Energy Chem., 2016, 25, 805-810.

46 G. Y. Fan, L. Zhang, H. Y. Fu, M. L. Yuan, R.-X. Li, H. Chen and X. J. Li, Catal. Commun., 2010, 11, 451-455.

47 J. Fan, K. Qi, L. Zhang, H. Zhang, S. Yu and X. Cui, ACS Appl. Mater. Interfaces, 2017, 9, 18008-18014.
48 L. Zhu, T. Zheng, C. Yu, J. Zheng, Z. Tang, N. Zhang, Q. Shu and B. H. Chen, Appl. Surf. Sci., 2017, 409, 29-34.

49 T. Patra, S. Ahamad and S. Upadhyayula, Appl. Catal., A, 2015, 506, 228-236. 